\title{
SAÚL TABORDA: DEBATES SOBRE LA CRISIS, LA ESTÉTICA Y EL REFORMISMO (1885-1944)
}

\author{
Myriam Southwell ${ }^{1}$ \\ Universidad Nacional de La Plata - Argentina \\ myriamsouth@msn.com \\ Nicolás Arata ${ }^{2}$ \\ Universidad de Buenos Aires - Argentina \\ Grupo de investigación HISULA \\ nicolasarata@yahoo.com.ar
}

Recepción: 15/09/2010

Evaluación: 03/04/2011

Aceptación: 30/11/2011

Artículo de Reflexión

\section{RESUMEN}

El presente artículo surge en el marco del proyecto "La educación sentimental: la estética escolar argentina de la primera mitad del siglo XX" proyecto financiado por la Agencia Nacional para la Ciencia y la Tecnología (ANPCyT) y que se desarrolla en tres universidades argentinas (la de Buenos Aires, la de La Plata y la de Rosario). El propósito específico de este trabajo es analizar el pensamiento pedagógico de Saúl Taborda, un intelectual forjado al calor del movimiento reformista universitario, de significativa presencia en el escenario latinoamericano y que ensayó propuestas reformadoras dirigidas al sistema escolar. Tres dimensiones

1 Profesora y Licenciada en Ciencias de la Educación, graduada en la Universidad Nacional de La Plata. Realizó estudios de Maestría en FLACSO, Sede Académica de Argentina y su doctorado en la Universidad de Essex (Inglaterra).

Profesora Titular de la Cátedra de Historia de la Educación Argentina y Latinoamericana en la Facultad de Humanidades y Ciencias de la Educación de la Universidad Nacional de La Plata, Argentina. Carrera de Investigador Científico y Tecnológico del Consejo Nacional de Investigación Científica y Tecnológica.

2 Nicolás Arata es Magíster en Ciencias Sociales con orientación en Educación (FLACSO Argentina). Licenciado en Ciencias de la Educación (Universidad de Buenos Aires). Docente de Historia de la Educación Argentina y Latinoamericana (FFyL, UBA). Candidato a doctor en Educación en la UBA y por DIE/CINVESTAV (México). 
analíticas serán centrales en la presentación del pensamiento tabordiano: la propuesta comunalista, una perspectiva emancipadora hacia los jóvenes y su participación en las instituciones escolares y la relevancia de la estética como dimensión formativa para los jóvenes.

Palabras clave: Revista Historia de la Educación Latinoamericana, Saúl Taborda, comunidad, estética.

\title{
SAUL TABORDA: DISCUSSION ON THE CRISIS, THE BEAUTY AND THE REFORMISM (1885-1944)
}

\author{
Myriam Southwell \\ Universidad Nacional de La Plata - Argentina \\ myriamsouth@msn.com \\ Nicolás Arata \\ Universidad de Buenos Aires - Argentina \\ Research group HISULA \\ nicolasarata@yahoo.com.ar
}

\begin{abstract}
ABSTRATC
This article is a result from a research project about "Sentimental education: school aesthetics during the 1900-1950 in Argentina" founded by Agencia Nacional para la Ciencia y la Tecnología (ANPCy'T) and it was developed in three argentinian universities (Buenos Aires, La Plata and Rosario). The main purpose is to analyze pedagogical thought of Saúl Taborda, who was an active intellectual from university reformism movement -widely aknowledged in Latin America- and who developed renewal challenges in schools. Three dimensions will be crucial in order to sumarize Taborda's ideas: a proposal about comunalism, an emancipatory point of view about young people in school organization and aesthetics as a central formative dimension.
\end{abstract}

Key words: Journal of Latin American Education History, Saúl Taborda, community, aesthetics. 


\title{
SAÚL TABORDA: DEBATES SOBRE A CRISE, A ESTÉTICA E O REFORMISMO (1885-1944)
}

\author{
Myriam Southwell \\ Universidad Nacional de La Plata - Argentina \\ myriamsouth@msn.com \\ Nicolás Arata \\ Universidad de Buenos Aires - Argentina \\ Grupo de pesquisa HISULA \\ nicolasarata@yahoo.com.ar
}

\section{RESUMO}

O presente artigo surge no marco do projeto "A educação sentimental: a estética escolar argentina da primeira metade do século XX", projeto financiado pela Agencia Nacional para a Ciência e Tecnologia (ANPCyT) e que se desenvolve em três universidades argentinas (a de Buenos Aires, a do Prata e a de Rosário). O propósito específico deste trabalho é analisar o pensamento pedagógico de Saúl Taborda, um intelectual forjado no calor do movimento reformista universitário, de significativa presença no cenário latino-americano e que ensaiou propostas reformadoras dirigidas ao sistema escolar. Três dimensões analíticas serão centrais na apresentação do pensamento tabordiano: a proposta comunista, uma perspectiva emancipadora para os jovens e sua participação nas instituições escolares e a relevância da estética como dimensão formativa para os jovens.

Palavras-chave: Revista História da Educação Latino-americana, Saúl Taborda, comunidade, estética.

\section{INTRODUCCIÓN}

Saúl Alejandro Taborda nació el 9 de noviembre de 1885 en la localidad rural de Santiago Temple, Córdoba (Argentina) y falleció en Unquillo (Córdoba) el 2 de junio de 1944. Estudió en la Escuela Normal de Córdoba y luego en el Colegio Nacional de Rosario. A partir de allí y por cierto tiempo su actividad transcurrirá entre las ciudades de Rosario y La Plata. En 1908 se trasladó a La Plata donde se graduó de abogado y en 1913 se doctoró en Derecho y Ciencias Sociales en la Universidad del Litoral. En esa Universidad se desempeñó como profesor de Sociología y en 1921 fue designado rector del Colegio Nacional de La Plata. Simultáneamente, fue Consejero de la Facultad de Derecho y 
Ciencias Sociales de Córdoba; allí impulsó la creación del Seminario de Filosofía y Humanidades, simiente de la actual Facultad de Filosofía y Humanidades. Dos años más tarde, partió a Europa donde permaneció hasta 1927, estudió en Marburgo (Alemania) con Paul Natorp, luego en Zurich, Viena y París. A su regreso a la Argentina se dedicó a la docencia aunque fuera de la Universidad y en 1942 fue designado como Director del Instituto Pedagógico de la Escuela Normal Superior de la provincia de Córdoba.

Su obra escrita comienza con la literatura ${ }^{3}$ y luego incursiona en el análisis ensayístico con su trabajo Reflexiones sobre el ideal político de América en 1918, abordando temas más filosóficos y sociológicos como la crisis de la civilización desarrollada bajo los preceptos europeos y la apertura a la hora de América. Allí reflexiona sobra los sistemas sociales, las formas estaduales, las instituciones políticas, civiles, educativas de la civilización europea, a la que la declara "inepta para realizar las nuevas concepciones del espíritu”. Esos análisis y su mirada sobre la historia argentina y la necesidad de revisión de los relatos históricos y sus rearticulaciones hacia el futuro son desarrollados también en La crisis espiritual y el ideario argentino (1934) donde aborda las consecuencias de la I Guerra Mundial en todos los órdenes de la vida ${ }^{4}$, sus artículos de la revista Facundo y La argentinidad prexistente entre otros trabajos.

Probablemente su obra educacional publicada más significativa sean los volúmenes de Investigaciones Pedagógicas (compuestos por cuatro tomos) en los que recorre la historia educacional mundial hasta los comienzos del siglo XX, las relaciones entre iglesia y estado, el nacionalismo, las relaciones entre ciencias naturales y pedagogía, entre historia y pedagogía, sociología y pedagogía y los objetos pedagógicos del conocimiento. Sus obras han sido valoradas por ser el primer -filósofo- que introdujo a Carl Smichtt en idioma español, para comprender cómo se emancipaba no sólo el campo intelectual nacional, sino para proyectar transformaciones en el Estado, la Nación y la democracia. ${ }^{5}$ Asimismo, a través de la incorporación

3 Su primer libro fue Verso Profano que se publica en La Plata en 1909 y reúne pequeños trabajados aparecidos con anterioridad en diarios y revistas. En 1916 se publica en Córdoba La sombra de Satán, un "episodio novelesco" de la vida colonial cordobesa. Dos años después se publica su novela Julián Vargas, que presenta una pintura de intereses políticos y económicos y una perspectiva crítica hacia la Universidad en los momentos previos a la reforma universitaria. A ello se suman algunos ensayos: La experiencia mística en la poesía de Teixeira de Pascoaes y de Rilke (1932), y cuentos como El caracol marino (1932), El dolmen y Calempluy (s/d).

${ }^{4}$ La Crisis espiritual y el ideario argentino, es una compilación de conferencias de Taborda.

5 Sobre este aspecto ver: DOTTI, Jorge E. (1998): "Filia comunitarista versus decisionismo". Saúl Taborda y los comienzos de la recepción de Carl Scmitt en la Argentina, en: Revista Prismas, Anuario de Historia intelectual. No. 2. Buenos Aires, Universidad Nacional de Quilmes. 
de figuras como Fichte y su reflexión sobre los lenguajes y la estética generó una renovación y reintroducción del humanismo en la filosofía y pedagogía argentinas articulándolo con las tradiciones telúricas, sobre otra construcción de nacionalidad, con la opción de la "Patria Grande Latinoamericana" y de propuestas formativas espiritualistas, superadoras del racionalismo restringido del siglo XIX.

Nos interesa aquí explorar su pensamiento en el contexto particular de los debates de la primera mitad del siglo XX -en particular durante el período de entreguerras- cuando se pusieron en discusión algunos aspectos centrales del ideario republicano-civilizatorio que habían dado origen al Sistema Educativo en el siglo anterior e interpelaron a lo escolar respecto a nuevas sensibilidades y nuevos modos de conocimiento. De este modo, nos interesa leer su obra como parte de las operaciones pedagógicas, los ideales de ciudadanía y moralidad que pugnaban por volverse hegemónicos y los patrones de selección y valoración estética ${ }^{6}$ que se desarrollaron como parte de las tensiones en los procesos de modernización cultural y social.

\section{Ubicación socio-histórica de su producción}

Analizaremos la intervención conceptual de Taborda en torno a cuatro ejes: su discusión con el pensamiento positivista que dominó el campo intelectual en la transición entre siglos, su confrontación con las diferentes formas del clericalismo y el dogmatismo, su preocupación por articular la noción de nación con otros significados que no fueran el modelo europeizante y sus propuestas en torno a una pedagogía facúndica.

Taborda criticó fuertemente al positivismo en tanto concepción muy presente en las Universidades latinoamericanas y también lo cuestionó en el modelo experimental de las universidades norteamericanas pensadas en torno a la suma de actividades con múltiples facultades y escuelas anexas, en las que se estudió de todo, pero con fines prácticos. Sus críticas estaban dirigidas hacia quienes adherían a las doctrinas darwinianas, por un lado, en lo vinculado a las formas de la enseñanza y a los contenidos pedagógicos y aquello que calificaba como el sello positivista en el trabajo de los educadores que los convertía en administradores de la educación. Por otro lado, lo preocupaba el papel de la Argentina frente al creciente imperialismo no sólo en términos geopolíticos sino de concepciones de conocimiento, por

${ }^{6}$ Cabe aclarar que estamos considerando a la estética como un registro constitutivo e inescindible del conjunto de las experiencias de los sujetos individuales y colectivos que, por tales motivos, establece diversas relaciones de efectividad con otros registros sociales. Comprendemos a la estética como un constructo histórico-cultural que se constituye en uno de los campos de lucha por la imposición de formas de entender/concebir/actuar en el mundo y la jerarquización de unos repertorios sobre otros (Pineau, Serra, Southwell, 2009). 
el lenguaje mimetizado con las ciencias naturales para los hechos sociales y -en contraposición- el surgimiento de las ideas vitalistas y espiritualistas ${ }^{7}$.

Como lo caracteriza Jorge Dotti, Taborda abordó ideales anarquistas y socialistas y desde allí postuló una identidad nacional que tomaba distancia del entorno nacional oligárquico de comienzos de siglo XX, la generación denominada de las Ideas, nacida aproximadamente en el Centenario a la que cuestiona en su primera novela Julián Vargas. En su crítica hay una apelación a la reconstrucción del lenguaje pedagógico -en el sentido más amplio del término- que se inició con el movimiento de la Reforma Universitaria en 1918. Uno de los marcos de referencia centrales para entender la crítica social sostenida por Taborda es el movimiento intelectual, político y pedagógico que se organiza en torno a la Reforma Universitaria de $1918^{8}$ y se extiende -a través de la expansión del espiritualismo y el movimiento escolanovista- hasta mediados de la década del 40 inoculando el ideario reformista en el sistema educativo en su conjunto. Las referencias a la Nación, el federalismo, la espiritualidad (en términos filosóficos y laicistas) y una renovación de las formas de participación, desafiaron y renovaron el discurso pedagógico de su época, articulándolo profundamente con lo político y el reformismo social.

En sus distintas intervenciones Taborda combate a las aristocracias católicas, a la oligarquía liberal, positivista y cientificista. ${ }^{9}$ Asimismo,

7 Ver: BIAGINI, Hugo. (2000): "La Reforma Universitaria. Antecedentes y Consecuentes”. Colección el Hilo de Ariadna, Buenos Aires, leviatan. También: BIAGINI, Hugo (Comp.). (1999): La Universidad de La Plata y el Movimiento Estudiantil. Desde sus orígenes hasta 1930. La Plata: Editorial de la Universidad Nacional de La Plata.

8 Saúl Taborda fue partícipe del Manifiesto Liminar de la Reforma, en el que se denunciaba un "régimen académico anacrónico montado sobre el derecho divino del profesorado universitario". Se reclama allí el poder a la decisión de los estudiantes en una universidad democrática. El Manifiesto se dirigía a los hombres libres de nuestro hemisferio y anunciaba la vigencia de ideas a semejanza de las que fueron las de la Revolución de Mayo. Estas generaciones de estudiantes y profesores que compartían semejantes ideales propugnaban la renovación de la cultura, pero de manera conjunta a los saberes populares en contraposición a los pensamientos enclaustrados, burocráticos, utilitarios, a la universidad como mero salvoconducto de títulos habilitantes, a la frivolidad de los discursos sin compromisos, a la ausencia de éticas en la enseñanza. De allí que La Reforma extendiera el pensamiento de la gratuidad en la enseñanza, la autonomía universitaria en materia política, la calidad de la enseñanza, la periodicidad y la libertad de cátedras, la sensibilidad social y la mancomunión con la clase obrera, el pacifismo, la lucha antiimperialista, contra la oligarquía y el clericalismo.

9 Carlos Cossio, dirigente estudiantil reformista de la corriente "novecentista" lo acusa de promover en la Reforma Universitaria un tinte anárquico. Los "novecentistas" provenían del Colegio Novecentista, un grupo ligado a la Facultad de Filosofía y Letras de Buenos Aires que se inspiraban en Ortega y Gasset, Dórs y Alejandro Korn. Ver: FERRERO, Roberto. (1988): Saúl Taborda. De la Reforma a la Revolución Nacional. Córdoba: Alción Editora, p. 60. 
desarrolló su propuesta de una "democracia funcional", una democracia asentada en comunidades que han perdido las esperanzas en los órganos legislativos, en los partidos políticos, en los sistemas electivos cada vez más complejos, una democracia que tendía hacia el autogobierno ${ }^{10}$. También sus simpatías por el socialismo y su obsesión por el comunalismo nacional opuesto al oligárquico liberal, sus desagravios al fascismo mussoliniano y alemán, le valieron sanciones de gran parte de la intelectualidad nacional ${ }^{11}$.

El período histórico que se abre luego de la finalización de la Primera Guerra Mundial, inaugura una etapa de revisión y renovación vinculadas fundamentalmente a la idea de crisis, de modernización, el rol de los intelectuales y la política, la Nación, el antiimperialismo, los proyectos políticos de transformación social, la interpelación/representación de los grupos subalternos, en términos de clase, étnicos y/o etarios (obreros, campesinos, jóvenes), la idea de cultura como portadora de valores emancipatorios. Probablemente no se había puesto de manifiesto de forma tan evidente la "juventud de América Latina" hasta que la "vieja" Europa sintió el agotamiento de la Primera Gran Guerra. ${ }^{12}$ En ese contexto se desarrollaron complejas relaciones entre Nación, crisis y modernidad en una década en la que se despliegan formas contra hegemónicas de poder, respecto de sus precedencias (como el Estado oligárquico) y surgen formas de pensar críticas y alternativas al orden instituido, a los cánones y las genealogías desarrolladas con anterioridad. Las nociones de modernización y de Nación fueron articuladas con otros componentes: vitalismo, espiritualismo, intuición, misticismo, sensibilidad, estética.

La crisis desarrollada a partir de la Gran Guerra, la relativización de Europa como faro de la cultura y la creciente oposición a las agresivas políticas militares de Estados Unidos sobre la región fueron generando dudas, rumbos significativos y un novel continente de sentidos en el mundo de las representaciones. La etapa estuvo marcada por la puesta en crisis de algunas convicciones decimonónicas, la crisis económica, la pluralización de formas y expresiones culturales, la apertura de otras fuentes de conocimiento tales como la sensibilidad (atendiendo a la influencia

${ }^{10}$ Con respecto a la "democracia funcional" concepto desarrollado por Taborda en varios números de la Revista Facundo, en las que desarrolla la relación entre "comunalismo y federalismo", así como temas de carácter más político, según Ferrero, (1998): estaba pensado en relación a las experiencias soviéticas que ofrecían representación a diversos grupos de producción, antes de la consolidación del stalinismo. El federalismo estaba basado en estructuras políticas locales, también como ejemplo tomaba las experiencias soviéticas.

11 DEL BRUTTTO, Bibiana. (2004): "La idea de Nación como ideal pedagógico y el lenguaje educativo como accionario humanista en Saúl Taborda”. Mimeo.

${ }^{12}$ FUNES, Patricia. (2006): "Salvar la Nación. Intelectuales, cultura y política en los años veinte latinoamericanos”. Buenos Aires: Prometeo. p. 13. 
bergsoniana $\left.a^{13}\right)$. Ante las insuficiencias mostradas por el modelo racionalista, se presentó un escenario social y cultural particular para la enseñanza. En palabras de Funes "La Primera Guerra Mundial limó todas las mayúsculas decimonónicas: Razón, Civilización, Progreso, Ciencia”. ${ }^{14}$ Como destaca esa autora para los años '20 la revolución, el socialismo, el comunismo, el antiimperialismo, el corporativismo, la democracia y la modernidad fueron tópicos que recorrieron la reflexión de los actores que se ubicaron desde el campo de la cultura y la sociedad. Pero, especialmente, recayó sobre ellos la tarea de pensar y crear interpretaciones y lecturas en torno a la Nación, entidad de sentido conformada desde múltiples visiones y ambivalentes significados al calor de una discusión que atravesaba tanto el plano filosóficocultural como el político. La apertura de nuevos horizontes y metáforas de la época permitió romper con aquellas visiones endógenas y cerradamente nacionalistas que coadyuvaron a configurar los imaginarios y resortes sobre los que reposaban las historiografías nacionales y abrir canales de diálogo entre distintas tradiciones. En la perspectiva tabordiana, Europa había fracasado; ya no podía guiar al mundo y eso hacía que comenzara la hora de América con las enseñanzas que extraía de la historia ya que conocía el proceso evolutivo y las causas de la derrota europea.

Las críticas de Taborda también tuvieron como destinatarios el deterioro del Estado y -en general- el modelo institucional. Busca reemplazar la idea de imperium que se había consolidado bajo el concepto de soberanía estadual absoluta y cerrada y que desembocaba en el hecho de que cada Estado se transformara en una idea insolidaria, irresponsable y extraña a las sanciones del derecho internaciona $\left.\right|^{15}$. Con un nacionalismo que en Taborda coincidía con la crítica al positivismo a ultranza y que se desarrollaría en pro de un latinoamericanismo con elementos de neoidealismo, ya a fines de los años 30 y comienzos de los 40 ese nacionalismo

${ }^{13}$ Henry Bergson criticaba el mecanicismo positivista y el racionalismo gnoseológico, proponiendo la intuición como fuente de conocimiento de lo real. La realidad para Bergson es un proceso perenne de creación, sin principio ni fin, que no se presentaba dos veces en la misma forma, un fluir constante, sin división alguna de partes. El intuicionismo influyó fuertemente formas y contenidos gnoseológicos y estéticos. Una pedagogía asentada en la función moral que, sin menoscabar la función del pensamiento y la sabiduría, asienta su legitimidad en una diferente relación con los alumnos-discípulos-jóvenes.

${ }^{14}$ FUNES, Patricia. Óp., cit, p. 13.

15 "El Estado como instrumento de la clase capitalista es inconciliable con una sociedad de naciones y el conflicto chino japonés, debajo del cual se debate un afán febril de expansión económica, es la prueba más palpitante de la inocuidad del remedio escogido para superar la crisis del Estado". TABORDA, Saúl E. (1933): "La Crisis Espiritual y el Ideario Argentino". Conferencia pronunciada bajo los auspicios del Instituto Social. Publicado por el Instituto Social de la Universidad Nacional del Litoral. Santa Fe. R. Argentina. 
tomará la forma de facundismo ${ }^{16}$ y comunalismo ${ }^{17}$. La falla de Occidente, la caída de sus pueblos, la desviación de sus fundamentos centrales, la Iglesia conquistadora, el intelectualismo que separó el pensamiento de la fe y cuyas últimas consecuencias son la doctrina de Hegel y la racionalización de las creencias religiosas, la unidad de la razón abstracta, favoreció y fomentó el particularismo ligado a los intereses privados y a los designios de los partidos. El Estado surgido como producto de decadencia del ecuménico medieval, constituido y plasmado en continuos y sucesivos actos de fuerza, no ha sido nunca, en la realidad, otra cosa que una fiel expresión de los principios unilaterales que penetraban la vida social. Es un fenómeno genuinamente europeo y lo es precisamente porque, al desprenderse de los macrocosmos precedentes, cobró una estructura impuesta por las potencias económicas que dieron origen a los cuerpos sociales fijados y diferenciados en grandes demarcaciones territoriales ${ }^{18}$. "En el propio anbelo de constitución de una sociedad de naciones destinadas a asegurar la paz y la justicia internacional late todavía el sentido ecuménico de la vida"'. A partir de ese diagnóstico Taborda propone un retorno a lo ecuménico a través de su idea de comunalismo y discute, con ello, la presunción del carácter conservador de la tradición, ya que en su pensamiento ocupa un lugar vivificador y de renovación moral.

Taborda destaca que el propio Sarmiento y las generaciones de la independencia, ubicaron en la comuna a las organizaciones que hoy denominamos populares, la socialización y la educación de las generaciones jóvenes, de la misma forma que los inmigrantes de fines del siglo XIX que coincidían con las ideas anarquistas y socialistas. El hogar o mejor -el hogar comunal- en la enseñanza directa, condicionado por los contenidos morales; los representantes religiosos, o el templo; y la propia escuela, fueron los pilares comunales de la enseñanza. Esta es la fuente del comunalismo, un orden existencial que entraña a lo popular, generado por las tradiciones de cada espacio territorial. ${ }^{20}$ "Tenemos conciencia de ser una comunidad" dice en La crisis espiritual; comunidad espiritual dentro de la cual el argentino

16 Tanto la concepción del "facundismo", como del "comunalismo", y la cultura nacional fueron tratados por Taborda en conferencias y la publicación del Diario Facundo, en 1935. En estas publicaciones y otras que no se incluyen aquí, Taborda abordó los temas de la democracia, el socialismo y el nacionalismo.

${ }^{17}$ Saúl Taborda tuvo influencias de lecturas de Wilheim Dilthey de Ortega y Gasset en la revitalización de las ideas frente al anquilosamiento de las instituciones; también del antipositivismo y de las ideas pedagógicas del español Eugenio D’ors, y la provincia de Córdoba fue durante la década del 20 un asiento de las orientaciones vitalistas y el antiimperialismo cultural, en 1922 José Vasconcellos visitó la provincia pronunciando conferencias. Ver: DEL BRUTTO, Bibiana. (2004): Óp., cit, p. 7.

${ }^{18}$ DEL BRUTTO, Bibiana. (2004): Óp., cit, p. 8.

${ }^{19}$ TABORDA, Saúl. (1933): Óp., cit, pp.10-13.

${ }^{20}$ DEL BRUTTO, Bibiana. (2004): Óp., cit, p 9. 
de carne y hueso se realiza como persona en la comunión con los bienes y los valores que ella custodia. No existe hombre tocado de sentido ético que no sea esencialmente político. Somos esencialmente políticos. Nuestra vinculación con la comunidad es indestructible. Ella se manifiesta en la labor del educador que medita en la formación de la personalidad, en la obra del trabajo que crea productos, en la actividad del industrial que maneja el fondo económico de la nación, en la creación del artista que decanta las formas de la belleza, en la meditación del pensador que descubre senderos ideales y en la tarea del conductor que vela por los intereses comunes ${ }^{21}$.

Lo facúndico -como representación de las formas de vida más telúricas, recuperación de aquello avasallado por la adopción de modelos europeístas- fue para Taborda un concepto central para posicionarse en relación al proyecto educacional hegemónico inaugurado por Sarmiento con su enorme peso y perdurabilidad. A partir de lo que definía como lo facúndico construía su crítica sobre la noción de instrucción pública de cuño europeo-norteamericano y elaboraba una propuesta de redefinición y de redireccionamiento hacia el futuro.

Taborda cuestionaba lo que calificaba como una "confusión" sarmientina entre educación popular y educación primaria; su argumento era que la educación popular no podía ser reducida a la aplicación administrativa de la instrucción pública sino que ella implicaba al hombre en el oficio, en su clase y en su medio, es decir en su existencia concreta. En ese sentido, buscaba recuperar las tareas de los docentes que, afirmaba, "constituyeron las cimientes de la nacionalidad argentina, pero no la creada desde arriba sino la que arraiga la expresión del genio nativo y las que apuntan a la realización de nuestro destino". Desarrollaba así una perspectiva crítica hacia los modos en los que era concebida la instrucción pública, una institución capaz de formar, a un tiempo, el hombre faber y el ciudadano. La educación de esta forma significa un instrumento puesto al servicio de las instituciones y éstas lejos de ser medios para fines humanos, son en sí mismas y por sí mismas fines supremos. Estas ideas contradecían los ideales del humanismo, propugnado desde los días del Renacimiento, ya que para éste el ideal fue que las instituciones valen como medios al servicio de sus fines ${ }^{22}$.

Taborda analizó como errónea la política educativa del Consejo Nacional de Educación que se orientaba conforme a la fórmula de Spencer "el arte de formar buenos animales" y por su vocación utilitarista. Planteaba, por el contrario, una pedagogía que dejara atrás la finalidad del homo faber, que exacerbaba los valores económicos y que se sacrificaba ante el fetiche

${ }^{21}$ TABORDA. Saúl. (1933): Óp., cit, p. 45.

22 DEL BRUTTO. Bibiana. (2004): Óp., cit, p.12. 
de la técnica. Esta nueva pedagogía se nutría del "valor de la enseñanza de la vivencia" ética y estética y, por lo tanto, política. ${ }^{23}$

La desestimación del genio nativo -representado en la metáfora de lo facúndico- o lo que imprime el sello particular a nuestra fisonomía,

No ba sido comprendido por la política inmigratoria, ni por la presidencia del Consejo Nacional de Educación [...] El anhelo de la unidad espiritual de los argentinos que discurre como leit motiv en las elucubraciones del Consejo Nacional de Educación es algo que responde a la concepción del pueblo organizado como cerrada unidad politico económica. No es una concepción válida en los días que corren; es una concepción que ya bizo su ciclo. En el siglo XIX respondió a la idea del centralismo unitario ${ }^{24}$.

Contrariamente, propone el desarrollo de una educación con ética y la sustitución de la disciplina patriarcal por otro régimen que favoreciese el autocontrol. Esa concepción se nutría con la introducción de lecturas que en él se consustanciaron con el pensamiento social nacional en el que están presentes Fichte, Alfred Weber, Heller, Carl Schmitt, Hegel, Marx, Sorel y entre los nacionales el pensamiento de Carlos Astrada, Coroliano Alberini, Alejandro Korn, entre otros ${ }^{25}$.

Un aspecto central del posicionamiento de Taborda era su oposición a la compulsión a un modelo presentado como único posible -como afirma Silvia Roitenburd- sin anclaje en la tradición local, elusivo de las especificidades de los conflictos en tiempo y lugar; asimismo, su Temario del Comunalismo Federalista buscó incluir también la problemática de las desigualdades de clase ${ }^{26}$. Esta autora destaca que pese a sus posiciones vinculadas al socialismo y al anarquismo Taborda discrepaba con formas ortodoxas de la izquierda, por una parte, con el esencialismo proclive a diagnósticos internacionalizados y apostaba -contrariamente- a los análisis y las propuestas que tuvieran anclaje local. En ese sentido, su versión selectiva de la tradición, condensada en lo facúndico, invocaba un mito impulsor de una cultura nativa no entendida como perenne e inmutable, sino profundamente histórica, imbricada con el espíritu de cada época y sus imperativos morales. Asimismo, no apelaba a la retórica basada en el

${ }^{23}$ Sobre estos aspectos se detiene especialmente en el libro: TABORDA Saúl. (1951): Investigaciones Pedagógicas, Vol. II, Córdoba: ateneo Filosófico de Córdoba.

${ }^{24}$ TABORDA. Saúl. (1933): Óp., cit, p. 13.

${ }^{25}$ DEL BRUTTO. Bibiana. (2004): Óp., cit, p. 12.

${ }^{26}$ ROITENBURD, Silvia. (2007): "La hora de América en un horizonte de reforma. Saúl Taborda: Un Intelectual Alternativo", en: Revista electrónica de estudios latinoamericanos, Vol. 5, N. 18. Enero-Marzo 2007, p. 3.

${ }^{27}$ ROITENBURD. Silvia. (2007): Óp., cit, p. 4. 
sobreentendido de una Latinoamérica como totalidad sin diversidad, sino que señalaba la necesidad de analizar cada situación nacional; así, discrepaba con un internacionalismo sin respuestas para los conflictos específicos ${ }^{27}$.

\section{"Docencia emancipadora"28}

En 1921 Taborda desempeñó, por un breve tiempo, el cargo de Rector del Colegio Nacional "Rafael Hernández" de la Universidad Nacional de La Plata, al cual accedió con la intención de extender a la enseñanza secundaria los principios reformistas que se exigían para la enseñanza superior. Su desempeño estuvo marcado por la búsqueda permanente de innovaciones pedagógicas y, con ello, suscitó grandes resistencias.

El movimiento de renovación iniciado el año 18 , si no quiere concretarse a ser una vana intentona referida a los estudios universitarios, no puede olvidar que toda la enseñanza -jardines de infantes, escuelas primarias, colegios normales, liceos, colegios nacionales- está todavía en manos de pedagogos que sirven a una pedagogía sobrepasada, y que, mientras esto siga así, nada de bueno se puede hacer en orden a los llamados estudios superiores [...] Todo ese ordenamiento debe ser alcanzado por la acción reformista. Reducir esta acción a los institutos universitarios no sólo es acusar ignorancia del proceso formativo sino que también, y sobre todo, es favorecer el viejo criterio que ha mutilado siempre dicho proceso en mil partes diversas con propósitos y resultados contrarios a la enseñanz $a^{29}$.

Como director del Colegio, avanzó en propuestas que modificaran sustantivamente la organización institucional, el vínculo pedagógico entre adultos y jóvenes y -fundamentalmente- la introducción de mecanismos que posibilitaran dar voz, participación y autonomía a los estudiantes. Propuso la creación de "La Casa del estudiante", para el encuentro de profesores y alumnos que serviría como sede de la Federación Universitaria, como museo universitario para preservar la memoria histórica de la Reforma, y como lugar de encuentro para que se alcanzara la fusión con el movimiento obrero ${ }^{30}$, un lugar que sustituyese el extrañamiento en la comunidad educativa y que promoviese las relaciones entre estudiantes y educadores. También reclamaba que se crearan en la Facultad cátedras de Crítica y Práctica Pedagógicas ${ }^{31}$.

\footnotetext{
28 "Docencia emancipadora". (1918): fue el título de la intervención Saúl Taborda en un acto realizado en el Teatro Argentino de La Plata.

${ }^{29}$ TABORDA, Saúl. (1951): Óp., cit, p.110.

${ }^{30}$ BIAGINI, Hugo. (Comp.).(1999): "La Universidad de La Plata y el Movimiento Estudiantil. Desde sus orígenes hasta 1930". La Plata: Editorial de la Universidad Nacional de La Plata, p. 27.

${ }^{31}$ Diario El Argentino de La Plata, 4 de marzo de 1921.
} 
Era sumamente crítico con aquellas posiciones que tenían miradas impugnadoras hacia los jóvenes, la expresión de sus voces en el espacio público y su presencia como una fuerza autónoma y demandante:

Es justamente a esos educadores, [...] a los que, con más frecuencia oigo decir, en son de protesta, que los estudiantes argentinos sólo sirven para bacer huelgas. No se deciden a advertir que si la insurrección de los estudiantes bubiera carecido, y careciera boy mismo, de fuertes razones de ser, una tal expresión bastaría a otorgarle una justificación más que aceptable, plausible. Pues, si fuera cierto que ellos no sirven para otra cosa que para hacer huelgas a nadie que no sean sus mentores correspondería ser responsables de esa ineficacia. En todo caso, están de más los maestros que sólo quieren entenderse con estudiantes perfectos ${ }^{32}$.

Como decíamos, su gestión frente a esta institución se vio influenciada por el movimiento reformista y ello lo aplicó al cambio académico en lo referido tanto a las metodología de enseñanza como al cuestionamiento de los catedráticos más tradicionales; una ruptura con los cerrados círculos que se erigían en torno a las Universidades y una fuerte discusión acerca del nuevo rol que éstas debían desarrollar en relación con la vida políticocultural del país. Como ya se ha dicho en numerosos trabajos, los estudiantes exigían participar del gobierno de las Universidades y procuraban estrechar lazos con la clase obrera. Un ejemplo de ello fue la organización curricular en torno a producciones literarias y artísticas contemporáneas, donde introducían en sus discusiones a nuevos hombres de la literatura nacional. Asimismo, se incorporaban nuevas perspectivas epistemológicas y estéticas a través de la incorporación de filósofos de adscripciones distintas como Bergson, Croce y los neokantianos alemanes.

Su dirección de la institución se orientó por la apelación a la educación estética, la remoción de algunos profesores y la incorporación de otros vinculados al movimiento de reforma universitaria, la búsqueda de participación estudiantil en asuntos institucionales de todo tipo; el exaltamiento de la juventud como fuente de reflexión pedagógica se articulaba con un cuestionamiento a las formas tradicionales de autoridad al interior de las instituciones educativas. Estas propuestas alcanzaron rápidamente grandes resistencias en la presidencia de la Universidad Nacional de La Plata (en adelante: UNLP) y otros sectores tradicionales que

${ }^{32}$ TABORDA, Saúl. (1932): "Investigaciones Pedagógicas". Tomo I, Córdoba: Ed. Ateneo Filosófico de Córdoba, p. 79. 
habían sido desplazados por su gestión ${ }^{33}$. Ante esa acusación Taborda y el alumnado tomaron las instalaciones del colegio durante varias semanas para asegurar el dictado de las clases ante la clausura impuesta por el Presidente de la UNLP. El Consejo Superior lo separó de sus funciones, pero ellos permanecieron atrincherados. Con intervención del poder judicial, se rodeó el colegio, se le cortó el teléfono, la electricidad, el agua, hasta que casi dos meses después de su ocupación se desalojaron las instalaciones y se detuvo a sus ocupantes. A partir de este hecho, de su expulsión como rector y su proceso judicial nació el estigma de Saúl Taborda como "anarquizador".

Luego de su gestión al frente del Colegio Nacional, viajó a Alemania donde adquirió una sólida formación a la luz de importantes pedagogos, entre los cuales se destacó Eduard Spranger. La influencia de corrientes filosóficas en ascenso como la fenomenología y el pensamiento neokantiano, ofrecían nuevas concepciones a los pensadores nacionales con profundas preocupaciones sociales.

A su regreso de Europa, se integró a un nuevo proyecto pedagógico: la dirección del Instituto Pedagógico anexo a la Escuela Normal Superior provincial de Córdoba, creada por Antonio Manuel Sobral (1897-1971) ${ }^{34}$ en 1942, con la intención de formar docentes con una concepción escolanovista. Esa institución formaba parte de una propuesta más amplia que consistía en una reforma educativa propiciada por el mismo Sobral, como legislador cordobés, desde mediados de la década del 30. De esta manera, Taborda y Sobral, elaboran una propuesta pedagógica alternativa a la tradición normalista, menos prescriptivista y cientificista, articulando la práctica con la elaboración de un pensamiento enriquecido con ella. Representaba una apertura hacia

${ }^{33}$ Dice BIAGINI, Hugo. (1999): citando el documento de la Acusación contra el Dr. Saúl Taborda, que apareciera como mural con la firma de "Los estudiantes que aspiraban a la verdadera reforma del colegio" "La Asociación pro Cultura Secundaria -presidida por un militar-y un comité anónimo de alumnos del Colegio Nacional (...) denunciando que el Colegio se habia convertido en un centro de perversión moral e intelectual para la juventud, pues no se respetaban en él a los profesores y se caía en prácticas irreverentes como fumar y tocar la guitarra, decir obscenidades, reunirse con mujeres, oponerse a los obreros rompehuelgas o asistir libremente a clase. En semejante contexto, Taborda era tildado de traidor a la Patria, por supuestas simpatías con la Revolución Rusa, por propagar ideas libertarias y maximalistas. p. 60.

34 Antonio Sobral asumió en 1926 la dirección de una Biblioteca Popular en Villa María (Córdoba) desde donde creó la Universidad Popular. Después del golpe de estado de 1930, la Universidad desapareció pero Sobral creó el Instituto Secundario Bernardino Rivadavia, allí funcionó además el Primer Salón de Escultura y Pintura. En 1941 se creó la Escuela Normal Provincial Víctor Mercante y la Escuela de Comercio Joaquín V. González. En 1940 al asumir el gobernador Santiago Horacio Castillo la gobernación de Córdoba se puso en práctica las ideas pedagógicas de Saúl Taborda. Ver: DEL BRUTTO. Bibiana. (2004): Óp., cit, p. 13. 
transformaciones cualitativas y ofrecía, con su crítica, una concepción social que aspiraba a transformar los discursos tradicionales.

Esa experiencia estuvo marcada especialmente por una contraposición a los dogmatismos a través de la laicización de los valores culturales en contraposición al nacionalismo católico que tenía una presencia muy significativa y determinante en la provincia de Córdoba. Dos componentes más incluía esta propuesta: por un lado, la creación de condiciones para el desarrollo de la autonomía de los estudiantes y ejercicio crítico de la participación como un elemento estructurante de la pedagogía; por otro, el desarrollo de prácticas escolares entendidas en contexto de regionalización, imbricada en las particularidades locales y en diálogo con las expresiones y necesidades comunitarias ${ }^{35}$.

En este escenario, el pensamiento de Saúl Taborda, configuró el posicionamiento de un hombre que se preguntaba y analizaba las particularidades de la crisis del país. Su mirada establecía una recuperación y fortalecimiento de las tradiciones culturales y filosóficas de la Nación, y la preocupación por aspectos que se reconfiguraban en aquel escenario de crisis; se preguntaba por la juventud, la familia, la cultura, la pedagogía.

Es probablemente mediante el aporte de variadas expresiones literarias -Hermann Hesse, Romain Rolland, entre otros- cuando logra abordar de modo más integral, su cuestionamiento ante la pretendida evidencia de la familia como núcleo educador natural. ${ }^{36}$ En sus Investigaciones Pedagógicas él se planteaba, en relación a la beligerancia de los estudiantes durante la Reforma Universitaria del 18'

\begin{abstract}
¿Qué hicieron entonces los pedagogos de profesión? ¿Qué dijeron a la juventud insurreccionada que les negaba enérgicamente en Córdoba, en Buenos Aires, en Santa Fe y en La Plata? ¿Qué nuevas orientaciones, qué rectificaciones propusieron a su disciplina ante la prueba rotunda de la violencia que descalificaba toda su docencia? Casi todos, si no todos, recurrieron a la prudente sabiduría del buen callar. Enmudecieron los viejos maestros.... Guardaron silencio en el momento en que era necesario que hablaran los sostenedores de la fórmula 'la enseñanza para los pedagogos ${ }^{37}$.
\end{abstract}

${ }^{35}$ Sobre estos rasgos puede consultarse el trabajo de: ROITENBURD Silvia. (1997): "La Escuela Normal Superior de Córdoba: la transformación educativa desde un proyecto disruptivo 1914-1947", en: Revista Propuesta Educativa, No. 17. Buenos Aires: FLACSO, Ediciones Novedades Educativas, pp. 70-73.

${ }^{36}$ DEL BRUTTO. Bibiana. (2004): Óp., cit, p. 13.

${ }^{37}$ TABORDA, Saúl. (1932): “Investigaciones Pedagógicas”. Tomo I, Córdoba, Ed. Ateneo Filosófico de Córdoba. Los tomos I y IV de Investigaciones publicados en vida de su autor en: La Revista de la Universidad Nacional de Córdoba. Los tomos II y III, fueron incluidos con la publicación de la obra completa en 1951. 
Ante una concepción de "educación dogmática", que Taborda encontraba en el nacionalismo católico y en el positivismo predominante en diversos educadores, sustentada como legítima por la imposición de un modelo excluyente regido por valores únicos -los dogmas-, su pensamiento opuso la configuración de un modelo inscripto en un imaginario democrático ligado al movimiento de la "Escuela Nueva" con preocupaciones que iban más allá de aspectos metodológico-didácticos y que ofrecían una reflexión acerca de la transformación social, desde la escuela. La búsqueda de nuevas respuestas ante un orden mundial que concluía nuevamente en un conflicto bélico, se conformó como un eje desde el cual se pensaba la transformación educativa.

"cada acto pedagógico práctico supone algo permanente y constante que no depende ni de las circunstancias ni de los actores. Esa constante es una significación $y$, como significación, se concreta de modo puramente pedagógico cada vez que el maestro y el educando se ponen en relación. Que en muchas ocasiones se nos presente rodeado de condiciones tales que, a simple vista, parezcan atribuirle un acusado carácter subjetivo y variable, es cosa que no altera, en el fondo, su contenido específicamente pedagógico. De ese sentido específicamente pedagógico nacen reglas que constituyen la praxis pedagógica ${ }^{38}$.

Taborda, retomó el valor de la identidad nacional y de la hispanidad y, confrontando con el cariz que históricamente le había dado el nacionalismo católico a estos conceptos -con raíces de la España inquisitorial-propuso su reconceptualización desde un imaginario integrador, capaz de abrir a una sociedad más democrática, incorporando el capital cultural universal y a la vez apelando a la preservación de la tradición nacional, las peculiaridades de la cultura regional.

la nación es una forma de vida que se realiza en el tiempo. La realizan hombres concretos, coincidentes en la voluntad y el destino. Por lo tanto la nación es una forma de vida social esencialmente constituida por una peculiar estructura de ideales bumanos que se realiza en un tiempo bistórico y en un espacio determinado. ¿De qué modo se estructuran los ideales? Si los ideales correspondientes al individuo, a la persona y a la personalidad reflejan fielmente la galería de un etnos, sólo una afinada determinación de la relaciones $y$ de las interacciones de esos ideales y de la manera como ellos se traman y se conjugan diacríticamente con los ideales ecuménicos que comunican estilo a una época nos puede instruir de la naturaleza de la nación ${ }^{39}$.

${ }^{38}$ TABORDA. Bibiana. (1951): Óp., cit, p. 111.
${ }^{39}$ Ibídem., p. 112. 
En trabajos posteriores Taborda discutiría estas aseveraciones diciendo:

Propongo una escuela única, dúctil y flexible, tan dúctil y flexible como corresponde al ideal de la personalidad plena (...). La escuela única rígida ya no se menciona. (...) Digo, pues como usted: la mayor diversidad cabe dentro de la más absoluta unidad ${ }^{40}$.

De esta forma, Taborda debatía con el positivismo desde uno de sus centros principales, como era la UNLP. Para él, la pedagogía era ciencia espiritual, ni ciencia natural ni pura especulación ${ }^{41}$.

Las ciencias naturales sólo pueden aportar a la pedagogía la secuencia causa-efecto sin entrar al meollo mismo del acto educativo. Las ciencias espirituales muestran preferencias por el valor [...] y comprenden valores objetivados. [...] La pedagogía es una pedagogía de la cultura en tanto acota su campo en el intimo enlace del espíritu subjetivo con el espíritu objetivo y busca en el momento propiamente pedagógico. [...] Ahi donde el hombre interviene en otro hombre con el propósito de incrementar su formación se hace presente el objeto pedagógico [este objeto] [...] hace pedagógico todo lo que entre en su constitución ${ }^{42}$.

En su intercambio con otros intelectuales -como Alejandro Kornse refería a la reflexión pedagógica argentina cuestionando la concepción restringida propuesta por el positivismo. Explicaba que en la Escuela Normal de Paraná nació una "dirección pedagógica" que asumió un carácter "utilitario, positivista, determinista y pragmático". La caracterizaba como una creación autóctona "ribeteada con alguna fruslería comtiana o spenceriana" ${ }^{\prime 3}$.

Taborda apela a los desarrollos de Fichte ${ }^{44}$ para resolver la cuestión del saber y la voluntad:

Dos cuestiones fundamentales se plantean aquí. La primera es la de saber en qué consiste la voluntad pura y como se puede obtener. [...] La segunda inquiere sobre el principio y la esencia de la voluntad pura. [...] Fichte aspira a resolver estas cuestiones en sus relaciones con la vida real. [...] El arte educativo ayuda al hombre a ascender al grado más elevado, que es el de la moralidad, y lo conduce libremente en cuanto fomenta la autoactividad libre. [...] fundamenta la

${ }^{40}$ Esto puede encontrarse en la carta que Taborda escribe en respuesta a Alejandro Korn. Anexo documental del libro: MONTENEGRO, Adelmo. (1984): "Saúl Taborda". Ministerio de Educación y Justicia, Buenos Aires: Ed. Culturales argentinas.

${ }^{41}$ Ibídem., p. 17.

${ }^{42}$ TABORDA. Bibiana. (1951): Óp., cit, p.112.

${ }^{43}$ Ibídem., p. 211. 
pedagogía de acuerdo a la idea y se empeña en guardar rigurosa distancia con los elementos empíricos. [...] Educar es formar. El formar, en tanto es construir o alcanzar un perfeccionamiento adecuado, supone un concepto final. [...] $]_{2} A$ quién le pediremos esta idea? La naturaleza no la posee. Tampoco la posee la experiencia. Evidentemente hay que obtenerla por deducción lógica. Con el procedimiento metódico del conocimiento, desde luego. [...] Alude a un proceso según un punto final inasequible empíricamente. De acuerdo a lo dicho, resulta innegable el fundamento idealista, y consiguientemente filosófico de la pedagogía. [...] "Las ciencias filosóficas [...] constituyen el fundamento y no necesitan del auxilio de la psicología [...]. La psicología solo puede indicar el camino tal como acontece en los casos particulares dados, pero no puede señalar la marcha de la educación en general ${ }^{45}$.

Taborda entendía que la educación debía concebirse de la manera más amplia posible y que era una tarea de la pedagogía encontrar las maneras de integrar a la vida escolar las restantes expresiones culturales de la comunidad; sostenía, asimismo, que el educador no objetiva valores, sino que hace subjetivos valores que son objetivos. Sostiene -apoyando sus afirmaciones en la producción filosófica de Dilthey- que "...el educando posee un plan y bay que comprenderlo. ${ }^{46}$ Cuestionaba la especulación que dividía la tarea educativa en una actividad que determinaba un fin y en otra que determinaba los medios. Su concepción de cultura se basó en la idea de integración de dominios particulares que se hallaban en la dinámica histórica, en mutua y recíproca interdependencia; como tal desplegaba, entre otras, una función pedagógica

${ }^{44}$ Nos referimos al filósofo alemán J.A. Fichte (1762-1814) quien a partir de la filosofía de Kant, desarrollo un "idealismo subjetivo". Abandonaba la noción de Kant acerca de "la cosa en sî" por considerarla incognoscible y otorgaba al acto propio del espíritu aquel impulso del alma que Kant había referido a "la cosa en sí”. Para Fichte sólo el yo existía y las cosas exteriores -que podía ser entendidas como limitaciones- eran sólo autolimitaciones del yo. Se opuso al dogmatismo a través de una noción de ciencia en la que tanto los principios de la inteligencia como la objetividad se derivaban del yo; la objetividad subsistente en Kant fue suprimida por Fichte al plantear que sólo el yo existe. Su concepción tuvo derivaciones en términos de filosofía práctica, principalmente en el campo del derecho y la moral.

45 TABORDA. Bibiana. (1951): Óp., cit, p. 85.

${ }^{46}$ Este argumento se expande en Investigaciones Pedagógicas, Tomo II. 


\section{CONCLUSIÓN}

Notas sobre nuevos ejes conceptuales para la pedagogía

En el período histórico que hemos abordado a través de la figura de Saúl Taborda diversos intelectuales intentaron metáforas e imágenes ubicadas entre la subjetividad y la necesidad de objetivar los escurridizos sentidos de la Nación. Las referencias eran eclécticas: espiritualismos, idealismos, vitalismos, relativismos. Estas vertientes ensayaron por la vía de la metáfora, del análisis conceptual o del diseño de respuestas a la crisis una nueva configuración para la pedagogía y los modos de pensar la relación de la escuela con la sociedad. Taborda halló en el Facundo la clave formativa de una tradición. La forma viviente y nuda de su contrariado espíritu objetivo, a saber, la nacionalidad misma. En ese contexto, la Nación ya no fue considerada como un atributo o un perímetro que acompañaba o completaba al Estado, sino que es tomada como el espacio de condensación de las complejidades y contradicciones sociales en el contexto de una modernidad esquiva y ecléctica pero advertible.

Éste terreno de tensiones condujo al intelectual a repensar los vínculos entre sociedad y Estado, en una línea donde nociones como república, democracia, revolución, socialismo y corporativismo fueron leídos en otra clave, para desbrozar nuevos y alternativos caminos hacia la elaboración de principios de legitimidad bajo la premisa de que era posible "ser salvados" por la misma Nación que se está discutiendo. El carácter de "civilización" podía ser revisado, incluso invertido. Como afirma "los "años locos" lo eran menos por el fox troty el "desenfreno" que por la entronización de lo nuevo, como categoría esencial cargada de valores positivos en sí mismos". 47 El "espíritu nuevo" se deslizaría de las vanguardias estéticas a las políticas.

A partir de esos desarrollos conceptuales la pedagogía se planteó como praxis conducida de la formación del individuo en la época de la desintegración de la imagen tradicional del mundo, inspirada en ese ideal ecuménico. Con Dilthey, Taborda consideraba que el mundo del hombre como experiencia vital era clarificado por el arte, la historia y las ciencias abstractas. En tanto el artista comprende el alma ajena, por la objetivación de su obra nos hace participar en el mundo interior de la individualidad descubierta por él, de manera que su manifestación estética es el órgano de la comprensión de la vida, que expresa lo típico y lo esencial de la estructura anímica y lo típico y lo esencial de la estructura axiológica, donde se acusa toda fisonomía peculiar dentro del mundo de las relaciones sociales. Asimismo, discurre Taborda en sus Investigaciones Pedagógicas, los actos intencionales pueden dirigirse a otras personas o a la vida de la comunidad, tal como acontece en el amor, en

${ }^{47}$ FUNES, Patricia. (2006): Óp., cit, p. 20. 
la simpatía, en el darse generoso y en la más alta expresión amistosa, que es la conciencia moral de la solidaridad espiritual y de la corresponsabilidad de todas las personas.

Pensador de los problemas de orden político cultural -dentro del que articuló los del campo pedagógico- Taborda fue un participante activo en experiencias de reforma escolar. Taborda colaboró con los gremios docentes en la elaboración de proyectos legislativos de reforma educativa con una visión crítica y amplia en su disposición al intercambio, capaz de mostrar los nexos indisolubles entre el pensamiento doctrinario, la toma de posición ante los problemas mundiales y nacionales y el espacio de la cultura como trama articuladora. ${ }^{48}$ Sus ideas aún son muy apropiadas para el escenario de las últimas décadas en que afloró el peligro de la mercantilización educativa en todos los niveles de la enseñanza, propugnada por organismos internacionales; tecnocracias asimiladas a los lenguajes y acciones de un pensamiento conservador y la reducción de los diversos sentidos de la educación pública a restrictivas formas de utilitarismo.

\section{FUENTES}

TABORDA, Saúl. (1918): Julián Vargas. Córdoba, Imprenta La Elzeviriana.

TABORDA, Saúl. (1918): Reflexiones sobre el ideal político de América. Córdoba, Imprenta Elzeviriana.

TABORDA, Saúl. (1932): Investigaciones Pedagógicas. Tomo I, Córdoba, Ed. Ateneo Filosófico de Córdoba.

TABORDA, Saúl. (1933): La crisis espiritual y el ideario argentino. Santa Fe, (Argentina), Instituto Social de la Universidad Nacional del Litoral.

TABORDA, Saúl. (1951): Investigaciones pedagógicas. Tomo II. Córdoba, ateneo Filosófico de Córdoba.

TABORDA, Saúl. (1988): La argentinidad preexistente. Buenos Aires: Docencia. TABORDA, Saúl. (1998): “Artículos de Facundo”, en: Revista Estudios 9.

\section{REFERENCIAS}

BIAGINI, Hugo. (2000): La Reforma Universitaria. Antecedentes y Consecuentes. Colección El Hilo de Ariadna.Buenos Aires, Leviatán.

BIAGINI, Hugo. (Comp.).(1999): La Universidad de La Plata y el Movimiento Estudiantil. Desde sus orígenes hasta 1930. La Plata, Editorial de la Universidad Nacional de La Plata.

${ }^{48}$ ROITENBURD, Silvia.(2007): Óp. cit, p. 6. 
CIRIA, A. Y SANGUINETTI, H. (1998): Los Reformistas. Buenos Aires: Ed Jorge Alvarez.

DEL BRUTTTO, Bibiana. (2004): La idea de Nación como ideal pedagógico y el lenguaje educativo como accionario humanista en Saúl Taborda.

DOTTI, Jorge. (1998): "Filia comunitarista versus decisionismo. Saúl Taborda y los comienzos de la recepción de Carl Scmitt en la Argentina”, en: Revista Prismas. Anuario de Historia intelectual. No. 2. Universidad Nacional de Quilmes.

FERRERO, Roberto. (1988): Saúl Taborda. De la Reforma Universitaria a la Revolución Nacional. Córdoba, Ed. Alción.

FUNES, Patricia. (2006): Salvar la Nación. Intelectuales, cultura y política en los años veinte latinoamericanos. Buenos Aires, Ed. Prometeo.

KORN, Alejandro. Carta a S. Taborda. Anexo documental del libro: MONTENEGRO, A. (1984): "Saúl Taborda”. Ministerio de Educación y Justicia, Buenos Aires. Ed. Culturales argentinas.

MONTENEGRO, Adelmo. (1984): Saúl Taborda. Buenos Aires, Ed. Culturales Argentinas.

ROITENBURD, Silvia. (1997): “La Escuela Normal Superior de Córdoba: la transformación educativa desde un proyecto disruptivo 1914-1947”, en: Revista Propuesta Educativa, No. 17. Buenos Aires, FLACSO, Ediciones Novedades Educativas.

ROITENBURD, Silvia. (2007): "La hora de América en un horizonte de reforma. Saúl Taborda: Un Intelectual Alternativo" en: E-l@tina. Revista electrónica de estudios latinoamericanos, vol. 5, No. 18. Enero-Marzo 2007.

VÁZQUEZ, Juan. (1965): Saúl Taborda. Antología filosófica argentina del siglo $X X$. Buenos Aires, EUDEBA.

SOUTHWELL, Myriam; ARATA, Nicolás. (2011): "Saúl Taborda: debates sobre la crisis, la estética y el reformismo (18851944)" en: Revista Historia de la Educación Latinoamericana Vol. 13 No. 17, Tunja, Universidad Pedagógica y Tecnológica de Colombia, RUDECOLOMBIA, SHELA- HISULA pp. 263-283 